\title{
Could boron be used as coronavirus inactivation agent?
}

\author{
Orak $\mathrm{F}^{1}$, Gundes $\mathrm{A}^{2}$, Yalcinkaya $\mathrm{KT}^{1}$, Orak $\mathrm{Y}^{3}$ \\ Kahramanmaras Sutcu Imam University, Department of Microbiology, Kahramanmaras, Turkey. \\ drfilizorak@hotmail.com
}

Text in PDF www.elis.sk.

Dear Editor-in-Chief,

As it is known, the novel human coronavirus COVID-19 emerged in Wuhan, China, in late 2019 and has raised a great public health concern (1). These days, the effectiveness of some drugs on the virus is being investigated. Hlavaty et al mentioned prophylactic regimes of chloroquine, hydroxychloroquine and lopinavir/ritonavir for the prevention of COVID and for the prophylactic measures for the high risk groups. Their data offer valuable insights to help prevent the infection and for control practices (1). We would like to congratulate the authors for this successful article and make some contributions from another point.

Efforts for the prevention of the rapid spread of the new coronavirus, which forms a pandemic and development of emergency treatment protocols have also been accelerated. As no specific treatment is available for COVID-19, a special attention is paid to protection measures. Hand cleaning and obeying disinfection rules is crucial to stop the ongoing outbreak and to control this novel infectious threat. In recent years, disinfectants have gained an importance. It was shown that disinfectants including $62-71 \%$ ethanol, $0.5 \%$ hydrogen peroxide or $0.1 \%$ sodium hypochlorite can inactivate Severe Acute Respiratory Syndrome (SARS) coronavirus, Middle East Respiratory Syndrome (MERS) coronavirus or endemic human coronaviruses $(\mathrm{HCoV})$ within 1 minute and the ones with $0.05-0.2 \%$ benzalkonium chloride or $0.02 \%$ chlorhexidine digluconate were less effective (2). However, there are several reports about the increase of allergic dermatitis and ethanol-related contact urticaria syndrome among healthcare professionals using alcohol-based hand rubs (3). In addition, boric acid is highly preferred in the treatment of burns and surface level wounds as a mild antiseptic; furthermore, it is also one of the main ingredients in eye creams (4). The chromatographic behaviour of

${ }^{1}$ Kahramanmaras Sutcu Imam University, Department of Microbiology, Kahramanmaras, Turkey, and ${ }^{2}$ Kahramanmaras Sutcu Imam University, Research and Development Centre for University-Industry-Public, Turkey, and ${ }^{3}$ Kahramanmaras Sutcu Imam University, Department of Anesthesiology and Reanimation, Kahramanmaras, Turkey

Address for correspondence: F. Orak, MD, Kahramanmaraş Sutcu Imam University, Department of Microbiology, Kahramanmaras, 46100, Turkey. Phone: +90.506 .3371046$ boron compounds has been shown to be effective on phosphatidylcholine lipids (5). Therefore, we think that boron may be an inactivation agent against enveloped viruses such as COVID-19.

We studied the in vitro susceptibility of a solution containing $2 \%$ elemental boron at a $99 \%$ purity, dissolved in distilled water with an alkaline $\mathrm{pH}$ to candida species and molds. There was an excellent result of inhibiting the fungi at very low concentrations (submitted for publication).

In this sense we developed three hypotheses:

Hypothesis 1: Could boron solution with alkaline $\mathrm{pH}$ be an alternative to alcohol and other virucidal disinfectants in the hospital environment?

Hypothesis 2: Can boron be used in vaccination studies instead of formol for inactivation of the virus?

Hypothesis 3: Could boron prevent virus from adhering to alveoli?

\section{References}

1. Hlavaty T, Krajcovicova A. Novel unorthodox strategies to reduce the case fatality rate of COVID-19 in high risk groups including patients using ace inhibitors. Bratisl Med J 2020; 121 (7): 462-465. DOI: 10.4149/ BLL_2020_74.

2. Kampf G, Todt D, Pfaender S, Steinmann E. Persistence of coronaviruses on inanimate surfaces and their inactivation with biocidal agents J Hosp Infect 2020; 104 (3): 246-251.

3. Cimiotti $\mathbf{J}$ et al. Adverse reactions associated with an alcohol-based hand antiseptic among nurses in a neonatal intensive care unit. Amer $\mathrm{J}$ Infect Control 2003; 31: 43-48.

4. ECETOC (European Centre for Ecotoxicology and Toxicology of Chemicals). 1994 Reproductive and general toxicology of some inorganic borates and risk assessment for human beings. Technical Report No. 65 . Brussels: European Centre for Ecotoxicology and Toxicology of Chemicals.

5. Fan P, Stolte S, Gabel D. Interaction of organic compounds and boron clusters with new silica matrices containing the phosphatidylcholine headgroup. Analyt Methods 2014. DOI: 10.1039/c4ay00119b.

Received April 15, 2020. Accepted May 12, 2020. 